\title{
Experiential Learning Systems Analysis with Action Research and Soft Systems Methodology
}

\author{
Carlos Sanchez-Lozano \\ Cenfotec University, Costa Rica
}

\begin{abstract}
Different aspects of online learning environments have been widely studied, including motivation, instructional effectiveness and attrition rates, among others. Despite extensive research, the process of designing an effective online course that can be seen as a 'set of seamless aesthetic components that create a connected emotional flow', as Dewey proposed, is still a challenge. Such an experience would be the result of a careful combination of structure and interactions. While course structure in eLearning can be considered clearly defined, the dynamics that emerge from the interaction of students with other participants and with course elements such as information resources are not linear. This study uses action research along with data analytics and process mining in order to better understand how these emerging paths and underlying dynamics impact instructional effectiveness and student motivation in a postgraduate course in UX, which was designed as an experiential learning system. Action research was chosen based on its defining characteristic of bringing about change in the system while at the same time learning from the process of deriving the change. Observations and sequence analysis informed the creation of a conceptual model of the course using soft systems methodology in order to reach 'desirable and feasible' solutions and inform future design. Preliminary results show that soft systems methodology is an effective framework to develop meaningful conceptual models of experiential systems supported by data and process analytics. These models can be later used as tools for further analysis and refinement.
\end{abstract}

Keywords: analytics; eLearning; experience-design; process-mining; systems-thinking 